\title{
Avaliação da Acurácia Posicional do Mosaico Sentinel-2 para Análise de Aplicabilidade na Atualização da Base Cartográfica Contínua na escala 1:100.000 (BC100)
}

\author{
Evaluation of the Positional Accuracy of the Sentinel-2 Mosaic for Analysis of \\ Applicability in Updating the Continuous Cartographic Base on the Scale 1: 100,000 \\ (BC100)
}

\author{
Priscila Almeida de Oliveira ${ }^{1}$ e Priscila de Lima e Silva ${ }^{2}$
}

1 Universidade Federal Rural do Rio de Janeiro, Departamento de Engenharia, Seropédica, Brasil. priscilalmoliveira@gmail.com. ORCID:https://orcid.org/0000-0001-5802-0774

2 Universidade Federal Rural do Rio de Janeiro, Departamento de Engenharia, Seropédica, Brasil. priscilalimasilvaufrrj@gmail.com. ORCID: https://orcid.org/ 0000-0003-4582-9958

Resumo: A disponibilidade de geotecnologias tem estimulado a produção e o consumo de informações espaciais, aumentando a necessidade de validações para garantir a qualidade cartográfica. Este artigo tem como objetivo avaliar a aplicação de imagens do satélite Sentinel-2, que podem ser obtidas sem custos e em forma de mosaico temporal pela plataforma Google Earth Engine (GEE), para atualização da Base Cartográfica Contínua na escala de 1:100.000 (BC100) do Instituto Brasileiro de Geografia e Estatística (IBGE). Foi avaliada a acurácia posicional planimétrica, tomando como referência um ortomosaico do IBGE, com resolução espacial de $1 \mathrm{~m}$, utilizou-se o método de feições lineares Buffer Duplo. Foram analisadas as vias da Universidade Federal Rural do Rio de Janeiro (UFRRJ), campus Seropédica, as quais foram vetorizadas na imagem de referência e no mosaico em teste. Em seguida foram avaliadas as discrepâncias obtidas, considerando o Padrão de Exatidão Cartográfica para Produtos Cartográficos Digitais (PECPCD) e o Erro Padrão (EP), para escala 1:100.000, obteve-se como resultado classe A. A aprovação do mosaico temporal formado por pixels de dias diferentes, disponibilizado pelo GEE, motivou a validação dos arquivos brutos e do mosaico obtido pela plataforma Sentinel Hub (EO Browser), ambos formados por pixels do mesmo dia. Aplicouse a Análise de Variância (ANOVA) para comparar as discrepâncias entre as imagens e concluiu-se que estatisticamente não há diferenças. Mostrando que para a área de estudo, analisando as vias, as imagens brutas do Sentinel-2, o mosaico temporal GEE e mosaico Sentinel Hub são aplicáveis para a atualização da BC100.

Palavras-chave: Buffer Duplo. Imagens orbitais. Avaliação da qualidade cartográfica.

\begin{abstract}
The availability of geotechnologies has stimulated the production and consumption of spatial information, increasing the need for validations to guarantee cartographic quality. This article aims to evaluate the application of images from the Sentinel-2 satellite, which can be obtained free of charge and in the form of a time mosaic by the Google Earth Engine (GEE) platform, for updating the Continuous Cartographic Base on a scale of 1: 100,000 ( BC100) of the Brazilian Institute of Geography and Statistics (IBGE). The planimetric positional accuracy was evaluated, using an IBGE orthomosaic as a reference, with a spatial resolution of $1 \mathrm{~m}$, using the Double Buffer linear feature method. The routes of the Federal Rural University of Rio de Janeiro (UFRRJ), Seropédica campus, were analyzed in the reference image and in the mosaic under test, and then the discrepancies obtained were evaluated, considering the Cartographic Accuracy Standard for Digital Cartographic Products (PEC-PCD) and Standard Error (EP), were obtained as class A result of the PEC-PCD. The approval of the temporal mosaic formed by pixels of different days motivated the validation of the raw files referring to the same scene of the satellite in question and of the mosaic obtained by the Sentinel Hub platform (EO Browser), both formed by pixels of the same day. Analysis of Variance (ANOVA) was applied to compare the discrepancies between the images and it was concluded that there are no statistically differences. Showing that for the study area, taking into account the pathways, the raw images from Sentinel-2, GEE temporal Mosaic and Sentinel Hub Mosaic are applicable for updating the BC100.
\end{abstract}

Keywords: Double Buffer. Orbital images. Spatial data quality. 


\section{INTRODUÇÃO}

O uso de informação espacial tem crescido exponencialmente com a evolução de geotecnologias como o sensoriamento remoto, posicionamento por satélites, sistemas de produção cartográfica, sistemas de informações geográficas (SIG) e disponibilização pela web (webmapping) (DSG, 2018). Atualmente, o IBGE atende a necessidade de representação espacial do território nacional, produzindo e disponibilizando Bases Cartográficas Contínuas nas seguintes escalas: 1:25.000 (RJ25 e SC25), 1:100.000 (BC100), 1:250.000 (BC250) e 1:1.000.000 (BCIM) (IBGE, 2021). A BCIM e BC250 apresentam-se no formato shapefile completas no site, ou seja, cobrindo todo o território nacional. Já a BC100, atualmente disponibiliza bases divididas entre os estados de Sergipe, Espírito Santo, Roraima, Goiás, Distrito Federal e estados da Amazônia Legal.

No estado de Sergipe, de acordo com o IBGE (2019b): “A BC100_SE foi gerada a partir de interpretação de imagens dos satélites RapidEye obtidas em 2013 e 2014 e Sentinel-2 em 2019". As bases dos demais estados não estão disponíveis ou foram geradas em sua maioria a partir das antigas imagens RapidEye, bem como por informações de órgãos setoriais, federais, estaduais e parceiros. Devido a omissão de muitos estados brasileiros na BC100, o uso de imagens georreferenciadas do satélite Sentinel-2, as quais se encontram disponíveis e sem custos em diversas plataformas, podem contribuir para validação e atualização contínua de bases cartográficas, auxiliar análises ambientais como foco de queimadas, crescimento urbano, entre outros estudos.

O satélite Sentinel-2 disponibiliza suas cenas com resolução espacial de 10 metros no visível e resolução temporal de 5 dias (ESA, 2016). Atualmente, a plataforma digital da European Space Agency (ESA) disponibiliza os arquivos brutos das imagens Sentinel (acesse: https://scihub.copernicus.eu/dhus), a plataforma Sentinel Hub disponibiliza cenas corrigidas e em diferentes composições (acesse: https://apps.sentinelhub.com/eo-browser) e Google Earth Engine (GEE), além de disponibilizar os itens citados anteriormente, possui ferramentas que permitem o download de mosaicos temporais compostos por pixels de diversas cenas de um período pré-definido, contendo produtos em dois níveis. O produto Level-1C é ortorretificado e registrado geograficamente, e o produto Level-2A é corrigido na atmosfera com base no produto Level-1C (GEE, 2017; XU et al., 2020).

Apesar da grande disponibilização de informações espaciais, para o devido uso, é de extrema importância analisar a qualidade posicional desses insumos, tendo em vista que a criação e disseminação de produtos cartográficos se tornaram rápidas e, em alguns casos pode ter a qualidade cartográfica negligenciada (GALO, CAMARGO, 1994; SANTOS et al., 2015; NETO et al., 2017). A acurácia posicional é realizada por meio da comparação entre feições do produto avaliado com seu correspondente em um produto de referência (LA VEGA et al., 2016).

Assim como Vergara et al. (1999), diversos estudos avaliaram a acurácia posicional planimétrica pela comparação de pontos referência com seus homólogos no produto cartográfico testado. Alguns autores utilizaram pontos homólogos para validar imagens orbitais com base no Padrão de Exatidão Cartográfico PEC (BRASIL, 1984), como Celestino et al. (2007), Antunes e Siqueira (2013), Ferreira et al. (2016), Ferreira et al. (2017) e Frazão et al. (2017).

Nos últimos anos, Arcanjo e Anjos (2019), Júnior et al. (2019) e Menezes et al. (2019) avaliaram a acurácia posicional planimétrica de imagens orbitais pela metodologia de pontos homólogos utilizando o PECPCD (DSG, 2016). No estudo de Barbosa et al. (2017) foi avaliada a ortoimagem Sentinel-2A (MSI) em duas regiões de Minas Gerais, tendo como referência pontos homólogos em imagens de melhor resolução espacial. Em Alvinópolis, verificou-se que a ortoimagem é acurada posicionalmente para a escala 1:100.000 na classe A do PEC-PCD, conforme o Decreto $n^{\circ}$ 89.817/ET-CQDG. Já no caso da região de Viçosa, a ortoimagem Sentinel-2A (MSI) apresentou tendência, sendo assim, a mesma não foi classificada como acurada.

Pessanha e Antunes (2019) avaliaram a acurácia posicional planimétrica da ortoimagem do Sentinel2A (MSI) na região de Dom Pedrito, Rio Grande do Sul, tomando como referência pontos coletados em campo por receptores Global Navigation Satellite System (GNSS) e obteve como resultado classe A do PEC-PCD na escala 1:25.000, conforme o Decreto $n^{\circ}$ 89.817/ET-CQDG, os autores recomendaram o estudo de diferentes cenas do satélite Sentinel a fim de obter um maior número de informações referentes à geometria das imagens. 
Conforme Castejon et al. (2013), a validação de uma imagem pode ser realizada a partir de referenciais por amostras de pontos, linhas ou polígonos. Tveite e Langaas (1999) e Fonseca (2018) recomendam que essa avaliação seja feita entre feições lineares, que geralmente são mais presentes e bem distribuídas nos produtos cartográficos. De modo geral, em uma base cartográfica aproximadamente $80 \%$ das feições são lineares, o que justifica a importância dos métodos de avaliação da acurácia posicional que utilizam tais feições (MOZAS, ARIZA, 2011; ZANETTI et al., 2016).

Alguns autores propõem metodologias que possibilitam avaliar a qualidade usando feições lineares em vez de pontos como Abbas et al. (1995), Goodchild e Hunter (1997), Ferreira e Cintra (1999), Galo et al. (2001), Dal Poz et al. (2001), Vieira et al. (2002), Ramirez e Ali (2003), Mozas e Ariza (2011). Nos últimos anos, o método por feições lineares Buffer duplo vem sendo utilizado em alguns trabalhos como em Santos et al. (2015), Santos et al. (2016) e Cunha et al. (2019). A validação de ortoimagens da ferramenta Basemap do software ArcGIS realizada por Zanetti et al. (2016), mostrou que o método de avaliação da acurácia posicional planimétrica por feições lineares Buffer Duplo apresenta resultados semelhantes ao método tradicional por pontos, uma vez que, neste estudo, em ambos os métodos as ortoimagens foram classificadas como classe $\mathrm{B}$ na escala 1:10.000 do PEC-PCD, conforme o Decreto n ${ }^{\circ}$ 89.817/ET-CQDG.

Diante do exposto, esse artigo tem como objetivo analisar a aplicabilidade das imagens do satélite Sentinel-2 para geração e atualização da BC100, avaliando a acurácia posicional planimétrica pelo método de feições lineares Buffer Duplo, com o uso das vias da UFRRJ, comparando as discrepâncias obtidas às condições impostas pelo PEC-PCD, conforme o Decreto $n^{\circ}$ 89.817/ET-CQDG. O desenvolvimento deste trabalho, traz como diferencial a avaliação da acurácia posicional das imagens Sentinel-2A a partir de feições lineares e a análise da aplicação dos mosaicos temporais gratuitos para a atualização da BC100, que compõem o mapeamento sistemático brasileiro, o qual encontra-se parcialmente disponível no site do IBGE.

O uso de imagens provindas de diferentes plataformas é justificado pelo fato de o GEE gerar um mosaico temporal formado pelos melhores pixels, em relação a cobertura de nuvens, que podem ser extraídos de cenas obtidas em dias distintos, a partir de um período pré-definido no código, diferente das imagens brutas que não sofrem nenhum tratamento e da imagem provinda do Sentinel Hub que é tratada e disponibilizada com correções. As imagens disponibilizadas com diferentes tipos de tratamento serão avaliadas como forma de verificar se as correções e a integração de pixels obtidos em diferentes dias no mesmo mosaico promovem mudanças na qualidade da imagem.

\section{METODOLOGIA}

A primeira etapa da metodologia consistiu no download das imagens testadas e da imagem usada como referência, depois foram vetorizadas as vias da UFRRJ em todas as imagens. A partir da amostragem das linhas vetorizadas foi aplicado método Buffer Duplo no software livre QGIS. Por fim, os resultados foram testados estatisticamente. As etapas da metodologia são apresentadas no fluxograma (Figura 1) e serão detalhadas nas seções a seguir.

Figura 1 - Etapas realizadas na metodologia.

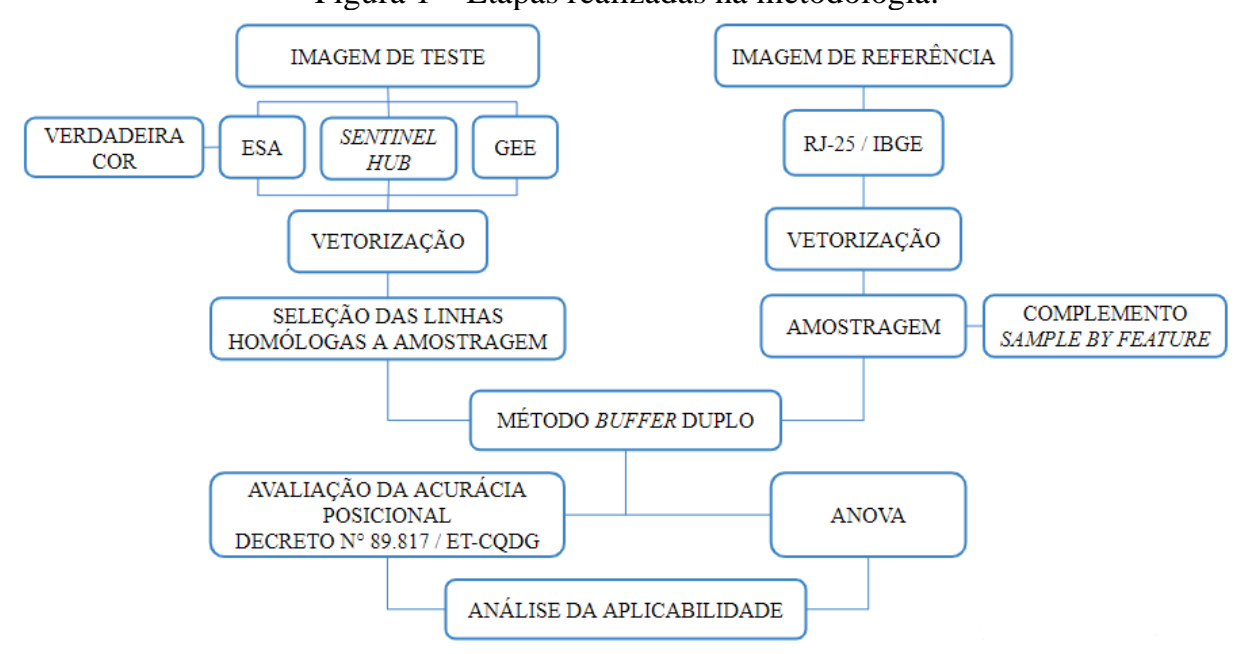

Fonte: Os autores (2021). 


\section{1 Área de estudo}

A área de estudo, representada na Figura 2, corresponde a parte central do campus da Universidade Federal Rural do Rio de Janeiro (UFRRJ), localizada no município de Seropédica, que é um dos maiores da América Latina com cerca 3.024 hectares. A escolha da área central se deu pelo fato de os autores conhecerem as vias vetorizadas, o que contribui para uma representação mais próxima da realidade.

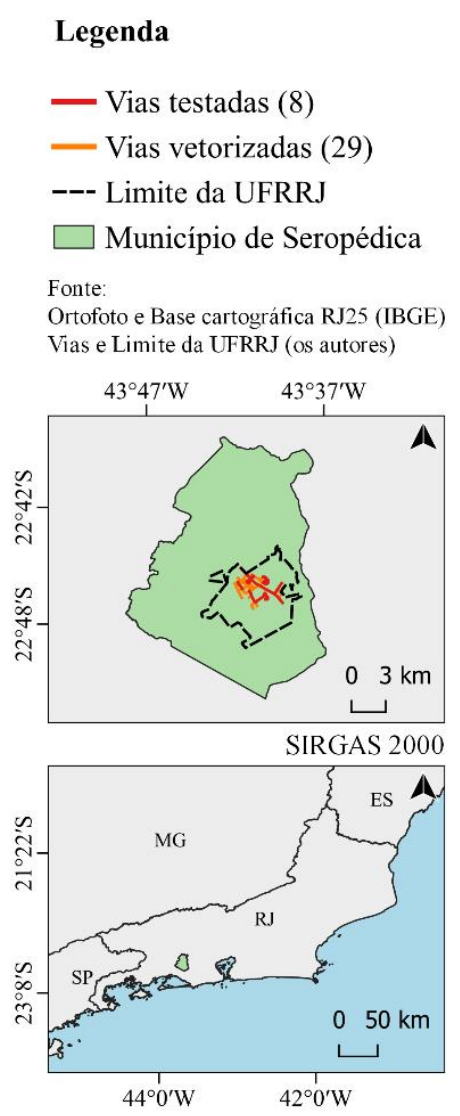

\section{Figura 2 - Área de estudo. \\ ÁREA DE ESTUDO DO CAMPUS DA UFRRJ}

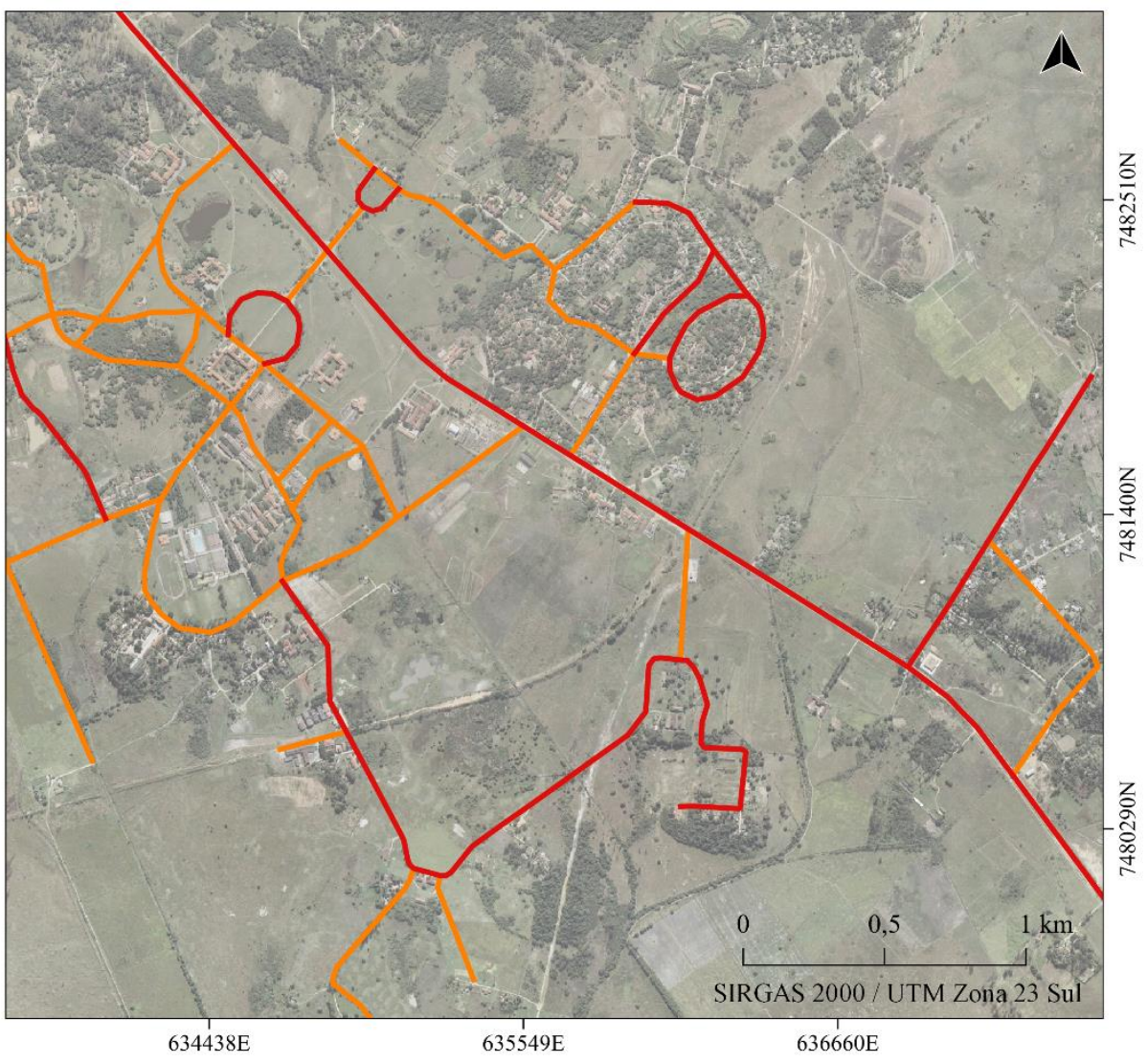

Fonte: Os autores (2021).

\subsection{Materiais}

Na avaliação da acurácia posicional planimétrica pelo método Buffer Duplo adotou-se como referência a ortofoto ofm_rj25_27444no_v1 do projeto RJ25 realizado em parceria da Diretoria de Geociências (DGC) e a Coordenação de Cartografia (CCAR) do IBGE. De acordo com os metadados deste produto (IBGE, 2010), para a tomada das fotografias aéreas, com escala aproximada de 1:30.000, foram realizadas campanhas de campo para levantamento de 1.300 pontos de apoio GPS (Global Positioning System) pelo método de posicionamento relativo estático. Todos os pontos levantados foram rastreados a partir de pontos da rede fundamental do IBGE, onde o erro médio do ajustamento foi menor que $30 \mathrm{~cm}$.

Ainda conforme IBGE (2010), as fotos foram ortorretificadas por meio de processos fotogramétricos analíticos digitais de aerotriangulação em bloco, para criação do Modelo Digital de Elevação (MDE) e retificação. Posteriormente, foram formados mosaicos segundo o recorte de folhas do mapeamento sistemático brasileiro, com a resolução final de $1 \mathrm{~m}$. Desta forma, para a validação das imagens Sentinel-2, adotou-se como referência um produto teoricamente 3 vezes melhor do que a BC100 (1:100.000), uma vez que à escala aproximada de obtenção das fotografias foi de 1:30.000.

Os satélites Sentinel-2A e 2B formam uma missão imageadora multispectral do programa Global Monitoring for Environment and Security (GMES) conjuntamente administrada pela Comunidade Europeia e a ESA para observação da Terra, foram lançados em $2015 \mathrm{com}$ altitude de $786 \mathrm{~km}$ e faixa imageada de 290 km. Os sensores S2A e S2B possuem resolução espacial de $10 \mathrm{~m}$ (20 e $60 \mathrm{~m}$ variando por banda espectral), 
resolução temporal (taxa de revisita) de 5 dias e resolução espectral de 13 bandas distribuídas no visível, infravermelho próximo e infravermelho curto (ESA, 2016; OLIVEIRA et al., 2019).

As imagens obtidas por sensoriamento remoto sofrem influências de diversos fatores atmosféricos devido à distância que separa a superfície terrestre do sistema sensor (REZENDE et al., 2017). Porém, o uso em pequenas escalas pode ser eficiente, considerando-se que técnicas de generalização são aplicadas geralmente para remover detalhes e representar espacialmente as feições (LONGLEY et al., 2013).

Dentre os serviços de computação em nuvem para análise científica e visualização de dados espaciais, o GEE vem ganhando destaque por ser utilizado em diversos estudos (GORELICK et al., 2017). O catálogo de produtos de sensoriamento remoto dessa plataforma possui extensas séries temporais de diferentes satélites, além de permitir ao usuário integrar seus próprios dados (SOUZA et al., 2019).

O GEE possui uma elevada capacidade de processamento e armazenamento, correspondentes ao ambiente computacional da nuvem Google, com um espaço de desenvolvimento que suporta implementações nas linguagens Java Script e Python para a análise e processamento de dados espaciais (GORELICK, et al. 2017). Por meio dessas linguagens, é possível obter um conjunto de cenas processadas com o objetivo de gerar um mosaico temporal com menor índice de cobertura de nuvens (OLIVEIRA et al., 2019).

Os comandos ilustrados na Figura 3 definem por meio da linguagem Java Scrip o acesso às imagens em verdadeira cor da biblioteca Copernicus, Level-2A, que apresenta como resultado uma média de pixels com menos de 10\% de nuvens no mês de abril de 2020 e na área previamente definida. Em seguida, o mosaico temporal é exibido na plataforma e exportado para o Google Drive (serviço de armazenamento e sincronização de arquivo), que pode ser facilmente acessado aos usuários do Gmail (serviço gratuito de webmail criado pela Google).

Figura 3 - Script elaborado no GEE.

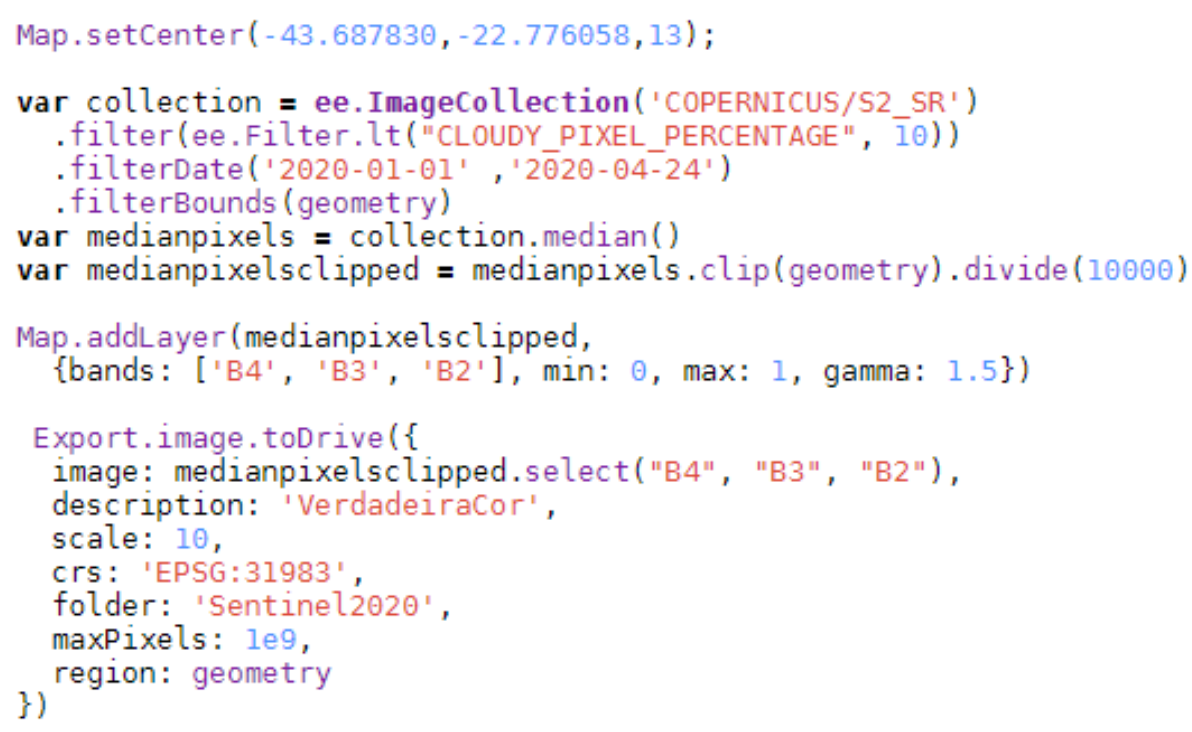

Fonte: Os autores (2021).

A fim de comparar o mosaico temporal do GEE com seus dados brutos, foi feito o download no site da ESA (Copernicus Open Access Hub) das bandas da cena correspondente a área de estudo no dia 13 de abril de 2020. O dia foi definido de acordo com a menor porcentagem de nuvens, a composição das bandas em verdadeira cor se deu por meio do complemento Semi Automatic Classification Plugin (SCP) do QGIS.

$\mathrm{O}$ último produto a ser testado foi o mosaico provindo do Sentinel Hub, esse website disponibiliza tanto os dados brutos, quanto as imagens processadas. Logo, fez-se o download do recorte da imagem corrigida e em verdadeira cor de acordo com a mesma área e data definida na última plataforma.

Vale ressaltar que todas as imagens e arquivos vetoriais foram definidos ou reprojetados para o sistema de referência SIRGAS 2000, projetados em UTM (Universal Transversa de Mercator) na zona 23 Sul. Em seguida, foram vetorizadas as vias do campus na imagem de referência e depois nas três imagens de teste para que fosse possível realizar a avaliação da acurácia posicional planimétrica. 


\subsection{Acurácia posicional planimétrica com referência no ortomosaico do IBGE}

A determinação da qualidade posicional de um produto pelo Decreto ${ }^{\circ} 89.817$ (BRASIL, 1984) e a Especificação Técnica para Controle de Qualidade de Dados Geoespaciais (ET-CQDG) é dado se as seguintes condições forem atendidas (SANTOS et al., 2015; DSG, 2016; CUNHA et al., 2019):

a) $90 \%$ das feições testadas devem apresentar valores de discrepâncias iguais ou inferiores ao valor do Padrão de Exatidão Cartográfica (PEC) estabelecido para a respectiva classe e escala;

b) O Erro Médio Quadrático (EMQ) da amostra de discrepâncias, deve ser menor ou igual ao valor do Erro Padrão (EP), também estabelecido para a mesma classe e escala.

A Tabela 1 expõe os valores das constantes, em milímetros, que devem ser multiplicadas pelo denominador da escala a ser testada para obter um limite de discrepância aceitável em determinada classe.

Tabela 1 - Valores da PEC e EP para planimetria.

\begin{tabular}{cc|cc}
\hline \multicolumn{2}{c|}{ Classes } & \multicolumn{2}{c}{ Planimetria } \\
Decreto n $^{\circ} \mathbf{8 9 . 8 1 7 / 8 4}$ & ET-CQDG & PEC-PCD & EP \\
\hline- & A & $0,28 \mathrm{~mm}$ x escala & $0,17 \mathrm{~mm} \times$ escala \\
A & B & $0,50 \mathrm{~mm}$ x escala & $0,30 \mathrm{~mm}$ x escala \\
B & C & $0,80 \mathrm{~mm}$ x escala & $0,50 \mathrm{~mm} \times$ escala \\
C & D & $1,00 \mathrm{~mm}$ x escala & $0,60 \mathrm{~mm}$ x escala \\
\hline
\end{tabular}

Fonte: Brasil (1984), Santos et al. (2015), DSG (2016) e Cunha et al. (2019).

Em razão do aumento da capacidade produtiva de informações espaciais, a inspeção completa dos produtos cartográficos tornou-se cada vez mais inviável, ocorrendo a demanda pela inspeção por amostragem e o uso de ferramentas estatísticas (MELLO, 2011). Especificamente nas inspeções de completude e acurácias (posicional, temática e temporal), em função da complexidade do produto cartográfico, geralmente, é necessário realizar inspeções amostrais, seja orientada por área, seja por feição geográfica, segundo um plano de amostragem bem definido (IBGE, 2019a).

Ainda segundo o IBGE (2019a), o plano de amostragem é definido com base no tamanho da população (N), no Nível de Qualidade Aceitável (NQA) e no Nível de Qualidade Inaceitável (NQI). Em geral, adota-se, inicialmente, o nível de inspeção II. Posteriormente, é recomendado que o nível de aceitação, baseado no Limite de Qualidade Aceitável (LQA) ou na Qualidade Limite (QL), se torne mais rígido (RIBEIRO, 2013).

A CCAR do IBGE desenvolveu os complementos Sample by feature e Sample by area para a elaboração de planos de amostragem, por feição e por área, dentro do ambiente de SIG QGIS. Onde é possível obter as amostras de acordo um nível de inspeção pré-definido pelo usuário, a partir de um arquivo que represente espacialmente a população dentro do software (IBGE, 2019a).

\subsection{Método de feições lineares por Buffer Duplo}

O método do Buffer duplo é efetuado aplicando-se o modelo da faixa de incerteza nas duas linhas utilizadas (linha de referência e linha de teste), ou seja, aplica-se um buffer em ambas as linhas e em seguida é realizada uma interseção entre os polígonos resultantes dos buffers (Figura 4), obtendo-se assim uma medida de discrepância média entre as feições lineares. A partir dos resultados obtidos na etapa supracitada, é possível avaliar posicionalmente a acurácia do dado espacial em teste (SANTOS et al., 2016; NETO et al., 2017). 
Figura4 - Método Buffer Duplo.

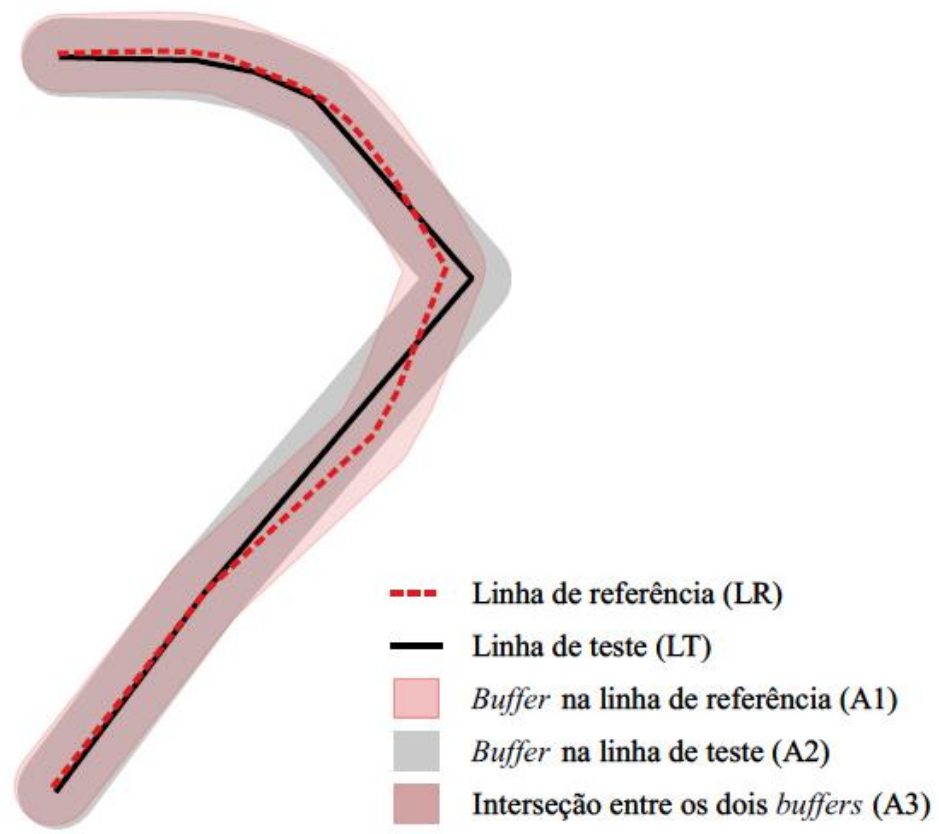

Fonte: Adaptado de Santos et al. (2016) e Cunha et al. (2019).

Santos et al. (2015), Neto et al. (2017) e Moreira et al. (2018) sugerem a aplicação do método do Buffer Duplo em conjunto com o padrão Decreto ${ }^{\circ}{ }^{8} 89.817 /$ ET-CQDG por meio das seguintes etapas:

a) selecionar uma amostra de $n$ linhas homólogas de teste (LT) e de referência (LR);

b) aplicar um buffer de tamanho $x$ em cada linha $i$ da amostra de linhas homólogas de teste e referência. Para o emprego do Decreto $n^{\circ}$ 89.817/ET-CQDG, utiliza-se como tamanho do buffer o valor do PEC-PCD para a escala e a classe utilizada no processo de avaliação;

c) calcular a área total (A1 e A2) gerada pela operação de buffer em cada linha de teste;

d) fazer uma interseção entre os polígonos gerados pelos buffers da linha teste e da linha de referência e calcular a área correspondente ao valor de A3;

e) calcular a discrepância média $(\mathrm{dm})$ para cada linha teste (E. (1));

$$
d m=\pi \cdot x \cdot \frac{\sum(A 1-A 3)}{A 2}
$$

f) por fim, para análise do Decreto ${ }^{\circ}$ 89.817/ET-CQDG, é verificado se $90 \%$ das linhas testadas apresentam $d m$ menor ou igual ao valor do PEC-PCD e, em seguida, se o EMQ (Eq. (2)) é menor ou igual ao valor do EP. Se as duas condições forem aceitas, classifica-se o dado espacial de acordo com a classe e escala trabalhada, sendo essa correspondente ao $x$ utilizado para gerar os buffers na equação anterior.

$$
E Q M=\sqrt{\frac{\sum_{i=1}^{n}\left(d m_{i}\right)^{2}}{n-1}}
$$

onde $d m$ é a discrepância média para cada linha teste $(i)$ e $n$ é o número total de linhas testadas.

Considerando o fato da utilização de feições lineares, atualmente não existe norma ou padrão que definem tamanho amostral para a avaliação da acurácia posicional, bem como padrões de dispersão ou distribuição espacial (MOREIRA et al., 2018). Foi utilizado o complemento Sample by feature, citado da seção 2.3, para selecionar as amostras de acordo com o nível II de inspeção. A amostragem foi definida na imagem de referência e nas imagens de teste foram selecionadas as linhas homólogas.

Em seguida, foi aplicado o método Buffer Duplo, considerando como largura do buffer 28 metros, valor do PEC-PCD para a escala 1:100.000. Depois, com o intuito de avaliar estatisticamente a existência de 
diferenciação entre as discrepâncias apresentadas pelas três imagens testadas, aplicou-se Análise de Variância (ANOVA). O teste Shapiro-Wilk calcula uma variável estatística (W) que investiga se uma amostra aleatória provém de uma distribuição normal de acordo com os valores críticos (F) tabelados e calculados (SHAPIRO, WILK, 1965).

Segundo Hair Júnior et al. (2009), a ANOVA permite verificar a existência de diferenças entre grupos e determina se as médias de grupos diferem significativamente, no entanto não indica entre quais grupos a diferença é significativa. Assim, caso as diferenças sejam significativas, se faz necessário utilizar testes de comparações múltiplas, como o Teste Tukey, que consiste em determinar a menor diferença significativa entre a média de dois grupos (MONTGOMERY, RUNGER, 2002).

Os testes estatísticos descritos no parágrafo anterior foram aplicados por meio do software R. Por fim, os valores de discrepâncias encontrados foram analisados quanto às condições impostas pelo Decreto $\mathrm{n}^{\circ}$ 89.817/ET-CQDG, possibilitando avaliar a acurácia posicional das imagens testadas e verificar a aplicabilidade destas para a atualização da BC100.

\section{RESULTADOS E DISCUSSÃO}

As discrepâncias relacionadas a acurácia posicional das imagens sentinel-2 obtidas pela plataforma GEE que disponibiliza um mosaico temporal formado pela integração dos melhores pixels de um período prédeterminado, do mosaico corrigido do Sentinel Hub e das imagens brutas adquiridas no site da ESA sem correções serão apresentadas a partir da análise das linhas amostrais. O complemento Sample by feature, disponível no software QGIS, foi utilizado para a definir a amostragem, sendo apresentado na Figura 5 as vias amostrais.

Figura 5 - Amostras selecionadas pelo complemento Sample by feature. VIAS AMOSTRAIS TESTADAS

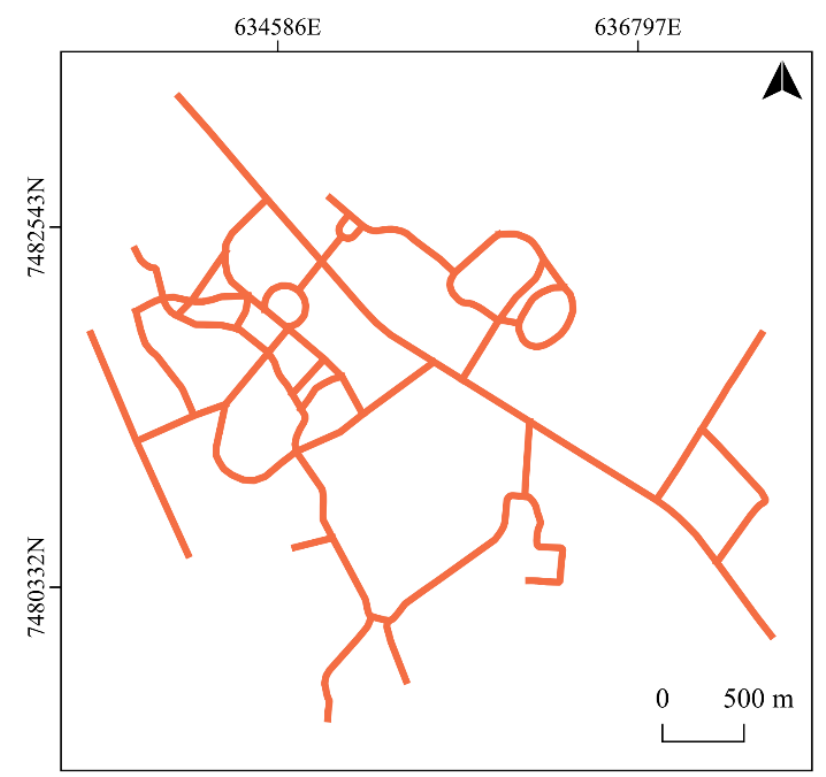

Legenda

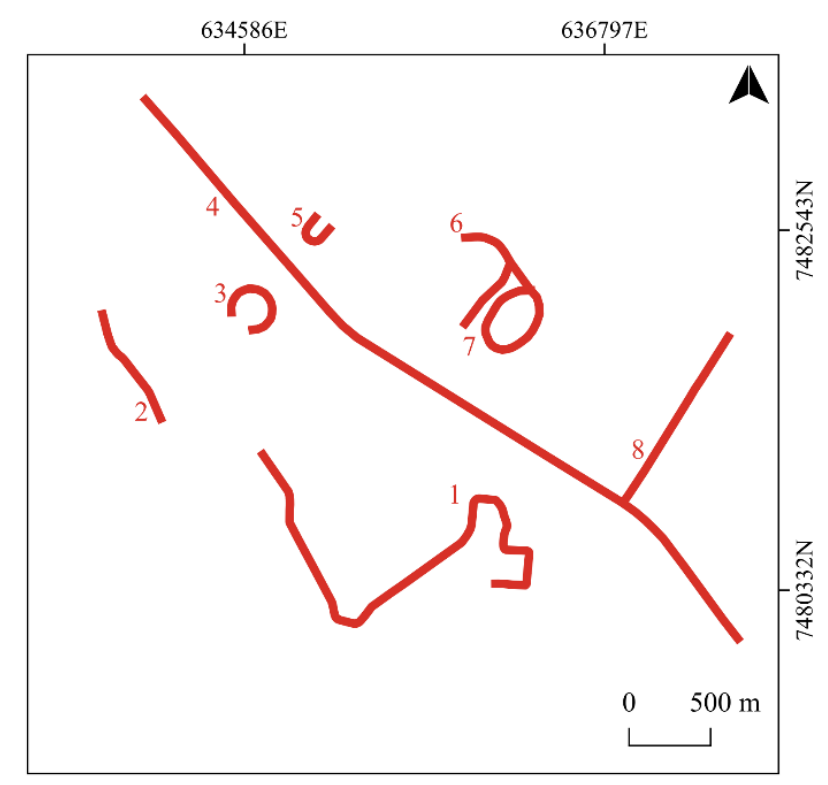

SIRGAS 2000/UTM Zona $23 \mathrm{~S}$

Vias vetorizadas

_ Vias selecionadas pelo Sample by feature

Fonte: Os autores (2021).

A Figura 6 ilustra, como exemplo, as vias vetorizadas na imagem de referência sobrepostas às que foram vetorizadas com o uso do mosaico temporal do GEE. A Tabela 2 apresenta os valores de discrepância encontrados ao aplicar o método do Buffer Duplo. 
Figura 6 - Amostras da imagem de referência e do mosaico temporal.
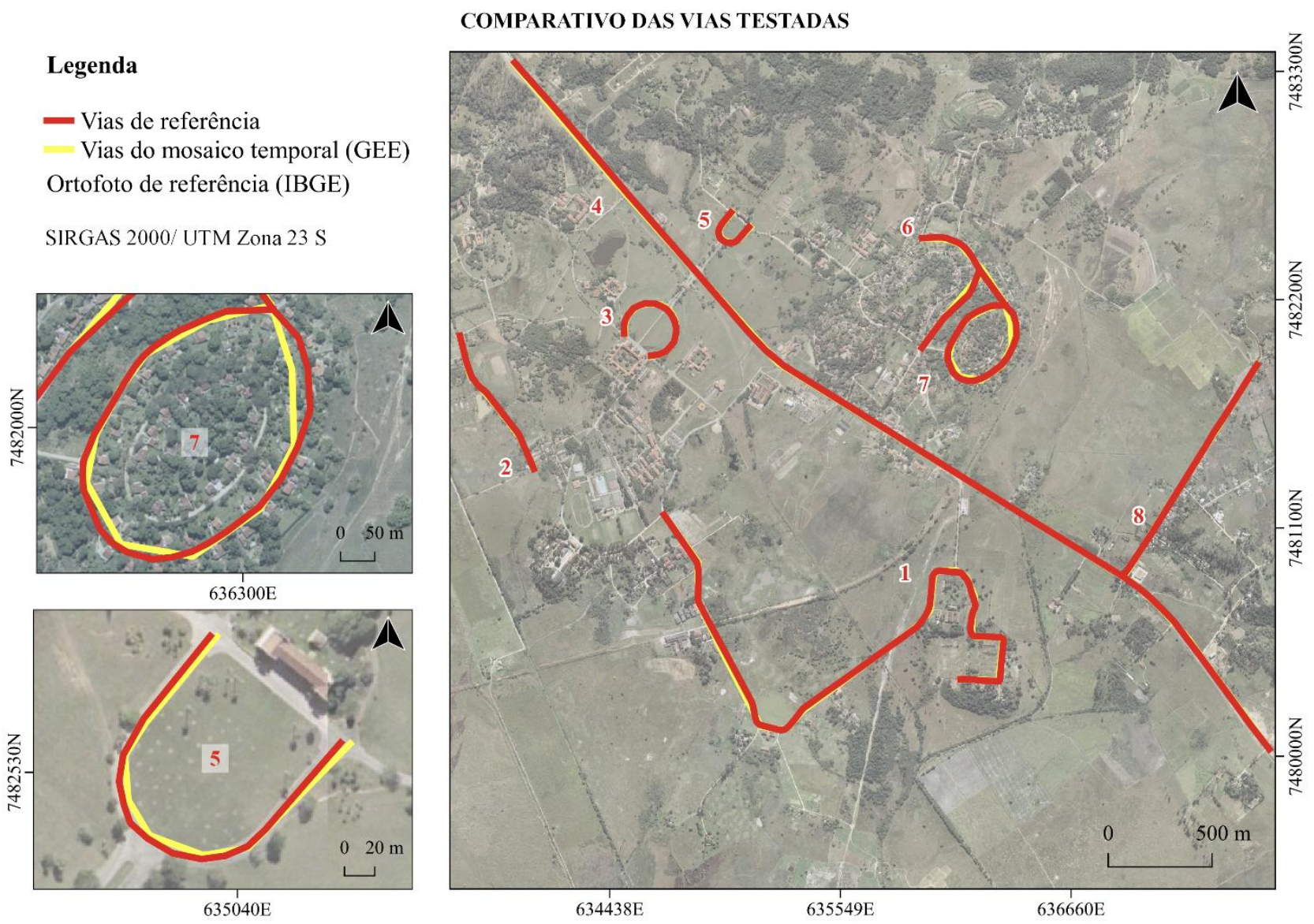

Fonte: Os autores (2021).

Tabela 2 - Discrepâncias do mosaico temporal o GEE em relação ao ortomosaico do IBGE.

\begin{tabular}{c|c}
\hline Linha & Google Earth Engine (GEE) \\
\hline 1 & 6,375 \\
2 & 2,915 \\
3 & 3,585 \\
4 & 4,844 \\
5 & 5,368 \\
6 & 8,811 \\
7 & 10,434 \\
8 & 1,968 \\
\hline
\end{tabular}

Fonte: Os autores (2021).

As linhas 2, 4 e 8 foram mais fáceis de identificar devido as geometrias menos curvas. Porém, observou-se um valor maior de discrepância na linha 4 que pode ter sido causado devido à sua extensão somado aos aspectos de generalização aplicados na vetorização, tendo em vista que esta é uma rodovia de mão dupla e que sofreu algumas obras entre os anos de obtenção da imagem de referência e as imagens de teste. Esse resultado destaca a importância de levar em consideração a acurácia temporal das imagens em relação aos objetos que serão testados na amostra.

Visualmente, percebe-se uma diferença mais acentuadas nas linhas 6 e 7. Acredita-se que isso se deu devido às linhas serem curvas e estarem mais próximas de árvores, o que dificultou à vetorização. Ainda na linha 7, nota-se que é fundamental a aplicação da generalização cartográfica. O que também pode ser observado pela linha 5 , onde a quantidade de vértices na linha de referência torna-se indiferente na escala do mapa central e, consequentemente, na escala 1:100.000.

Por outro lado, as linhas 3 e 5, apesar de curvas, apresentaram menores valores de discrepâncias devido a simetria que facilitou a vetorização e a menor quantidade de obstáculos em torno das vias. Esses fatos também correspondem a linha 1, porém os diferentes tipos de curvas e a sua extensão podem ter contribuído para os maiores valores de discrepância apresentados na Tabela 2. Além do mosaico obtido pelo GEE, foram avaliadas 
a imagem Sentinel Hub e os dados brutos disponibilizados pela ESA, sendo os valores de discrepância obtidos apresentados na Figura 7.

Figura 7 - Discrepâncias observadas para escala 1:100.000.

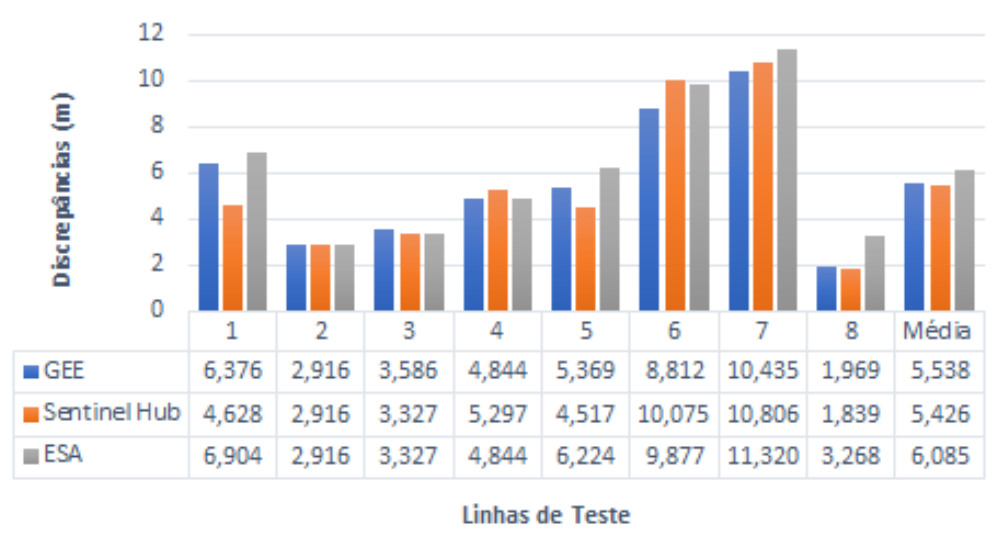

Fonte: Os autores (2021).

Tendo em vista os resultados apresentados (Figura 7), é possível notar que as imagens brutas da ESA apresentaram maiores valores de discrepância, essa ocorrência é explicada pela omissão das correções atmosféricas, o que resultou numa composição em verdadeira cor com resultado mais difícil para o olho humano identificar. Tais correções podem ser realizadas com os arquivos brutos e parâmetros disponibilizados pela ESA utilizando ferramentas existentes softwares de SIG. Enquanto as discrepâncias encontradas na imagem do Sentinel Hub e no mosaico temporal do GEE apresentaram discrepâncias com valores próximos entre si e menores que as imagens brutas, o que pode ser explicado pelos bons contrastes das imagens corrigidas que facilitaram o processo de vetorização das vias.

Nas análises estatísticas aplicadas, um dos requisitos para a ANOVA é que amostras avaliadas sigam distribuição normal, desta forma, as discrepâncias foram testadas estatisticamente pelo Shapiro-wilk normality test (Tabela 3), para o nível de significância de 0,05. Como resultado, rejeitou-se a hipótese nula de que os dados não seguem distribuição normal, uma vez que, nos três casos, todos os Valores $\mathrm{P}$ são maiores que o nível de significância e todos os $\mathrm{W}$ calculados são maiores que o ponto crítico (item 2.4), que equivale a 0,818 para 8 amostras.

Tabela 3 - Teste de normalidade das discrepâncias na escala 1:100.000.

\begin{tabular}{c|c|c}
\hline Imagem Sentinel-2 & W calculado & Valor P \\
\hline Google Earth Engine (GEE) & 0,949 & 0,705 \\
Sentinel Hub (EO Browser) & 0,855 & 0,108 \\
Agência Espacial Europeia (ESA) & 0,892 & 0,245 \\
\hline
\end{tabular}

Fonte: Os autores (2021).

Como as amostras seguem distribuição normal, avaliando as discrepâncias pela ANOVA (Tabela 4), é possível verificar que não há diferenças estatísticas entre as discrepâncias existentes para as três imagens testadas, visto que o valor P é maior que 0,1 (intervalo de confiança de $90 \%$ ) e o valor de $\mathrm{F}$ calculado é menor que o ponto crítico (item 2.4). Como não existiu diferença estatística entre as imagens, não foi aplicado o Teste Tukey.

Tabela 4 - ANOVA na escala 1:100.000.

\begin{tabular}{c|c|c|c|c|c|c}
\hline $\begin{array}{c}\text { Origem das } \\
\text { variações }\end{array}$ & $\begin{array}{c}\text { Soma dos } \\
\text { Quadrados }(\mathbf{Q M})\end{array}$ & $\begin{array}{c}\text { Graus de } \\
\text { Liberdade }(\mathbf{G L})\end{array}$ & $\begin{array}{c}\text { Quadrado } \\
\text { Médio }(\mathbf{Q M})\end{array}$ & Valor de F & Valor P & F crítico \\
\hline Entre as imagens & 1,989 & 2 & 0,995 & 0,102 & 0,903 & 3,467 \\
Dentre as imagens & 204,543 & 21 & 9,740 & & & \\
Total & 206,533 & 23 & & & & \\
\hline
\end{tabular}

Fonte: Os autores (2021).

As discrepâncias médias $(\mathrm{dm})$ observadas e as condições impostas pelo Decreto n ${ }^{\circ}$ 89.817/ET-CQDG, 
obteve como resultado, na avaliação da acurácia posicional, classe A na escala 1:100.000 do PEC-PCD para todas as imagens avaliadas. Todas as amostras do mosaico temporal do GEE, da imagem do Sentinel Hub e dos dados brutos provindos da ESA foram aprovadas nos requisitos de $90 \%$ das amostras com $\mathrm{dm}$ menor que $28 \mathrm{~m}$ e EMQ menor ao EP de $17 \mathrm{~m}$ (Tabela 5).

Tabela 5 - Estatísticas básicas das discrepâncias na escala 1:100.000.

\begin{tabular}{c|c|c|c|c}
\hline Imagem Sentinel-2 & Média $(\mathbf{m})$ & Mínimo $(\mathbf{m})$ & Máximo $(\mathbf{m})$ & EMQ $(\mathbf{m})$ \\
\hline Google Earth Engine (GEE) & 5,538 & 1,969 & 10,435 & 6,597 \\
Sentinel Hub (EO Browser) & 5,425 & 1,839 & 10,806 & 6,666 \\
Agência Espacial Europeia (ESA) & 6,085 & 2,916 & 11,320 & 7,229 \\
\hline
\end{tabular}

Fonte: Os autores (2021).

Os resultados apresentados motivaram uma avaliação em maior escala (1:50.000). Esta análise também atingiu classe A do PEC-PCD para as três imagens avaliadas. Conforme o Decreto ${ }^{\circ}$ 89.817/ETCQDG, foram satisfeitos os requisitos de $90 \%$ das amostras com $d m$ menor que $14 \mathrm{~m}$ e EMQ menor ao EP de $8,5 \mathrm{~m}$ (Tabela 6).

Tabela 6 - Estatísticas básicas das discrepâncias na escala 1:50.000.

\begin{tabular}{c|c|c|c|c}
\hline Imagem Sentinel-2 & Média (m) & Mínimo (m) & Máximo (m) & EMQ (m) \\
\hline Google Earth Engine (GEE) & 5,574 & 1,878 & 11,0730 & 6,705 \\
Sentinel Hub (EO Browser) & 5,482 & 1,767 & 11,439 & 6,772 \\
Agência Espacial Europeia (ESA) & 6,077 & 2,935 & 11,804 & 7,267 \\
\hline
\end{tabular}

Fonte: Os autores (2021).

Analisando a Tabela 6, pode-se perceber que as discrepâncias médias e os valores do EMQ na escala 1:50.000 mantiveram o comportamento apresentado na Tabela 5, ou seja, na escala de 1:100.000. Os resultados foram similares aos encontrados por Barbosa et al. (2017), que aprovou as imagens brutas do Sentinel-2, provindas do site da ESA, para a escala 1:100.000 em classe A do PEC-PCD, ao utilizar a comparação de pontos homólogos em imagens de melhor resolução. O método Buffer Duplo apresentou resultados mais restritos quando comparados a Pessanha e Antunes (2019) que aprovaram as imagens brutas do satélite Sentinel-2 ${ }^{\mathrm{a}}$ em classe A na escala 1:25.000 de acordo com o PEC-PCD, ao analisar pontos homólogos das imagens orbitais com pontos coletados em campo por GNSS. No entanto, os métodos de feições lineares cobrem de forma contínua e significativa a área em estudo, o que pode ajudar a restringir as análises estatísticas.

\section{CONCLUSÃO}

Os mosaicos Sentinel avaliados foram considerados acurados na escala 1:100.000, realizando a análise pelo método do Buffer Duplo, comparando as discrepâncias às condições colocadas pelo Decreto $\mathrm{n}^{\circ}$ 89.817/ET-CQDG. Portanto, podem ser utilizados para gerar e atualizar as vias da BC100, levando em consideração que, neste estudo, a área avaliada é relativamente plana, com vias de fácil identificação e de conhecimento do restituidor.

Pelos resultados encontrados, o GEE atende as necessidades de produções cartográficas na escala 1:100.000, bem como a atualização das bases cartográficas contínuas, assim como os outros dois produtos avaliados, a imagem Sentinel Hub e os arquivos fornecidos pela ESA, pois pela análise ANOVA, não existe diferença estatística entre os valores de discrepância apresentados pelas imagens. Porém, o GEE apresenta vantagem de possibilitar a obtenção de um mosaico temporal formado pela seleção dos melhores pixels em relação a quantidade de nuvens e formado por diversas cenas na mesma imagem no Level-2A, ou seja, com correção radiométrica, o que facilitou a caracterização dos pixels e, consequentemente, a vetorização das vias devido ao melhor contraste apresentado na imagem.

Os resultados encontrados são promissores, uma vez que as amostras também foram aprovadas na classe A na escala 1:50.000 de acordo com o Decreto ${ }^{\circ}$ 89.817/ET-CQDG, o que mostra maior aplicabilidade, considerando a qualidade posicional das imagens Sentinel-2. No entanto, estudos devem ser feitos em outras regiões do Brasil, com relevos diferentes, para avaliar a aplicação em todo o território brasileiro que é bastante heterogêneo. E considerando o mapeamento de outros elementos, além das vias, como hidrografia, linhas férreas e de transmissão. 
Pôde-se constatar, que o satélite Sentinel-2 atende a premissa da acurácia posicional planimétrica, mas outros aspectos de qualidade podem ser avaliados com o uso dessas imagens como a completude das informações presentes no conjunto de dados. A otimização do mosaico temporal disponibilizado pela plataforma GEE, onde os melhores pixels de algumas cenas são selecionados em um período de tempo prédeterminado facilita a busca pelas imagens orbitais com baixa cobertura de nuvens quando comparadas a imagens das plataformas Sentinel hub e ESA que disponibilizam imagens formadas por pixels obtidos no mesmo dia. Para o futuro, recomenda-se realizar análises de acurácia posicional das imagens Sentinel-2 em outras regiões, tendo como referência pontos coletados em campo, afim de verificar se os resultados seriam similares aos métodos de feições lineares.

\section{Agradecimentos}

Ao curso de Engenharia de Agrimensura e Cartográfica e a Universidade Federal Rural do Rio de Janeiro (UFRRJ) por todo o apoio e infraestrutura.

\section{Contribuição dos Autores}

Priscila Almeida de Oliveira realizou as etapas de investigação, coletas de dados, metodologia, análise dos dados, redação e revisão do artigo. Priscila de Lima e Silva revisou todas as etapas, contribuiu com o texto e auxiliou o desenvolvimento da metodologia.

\section{Conflitos de Interesse}

As autoras declaram que não há conflito de interesse.

\section{Referências}

ABBAS, I.; GRUSSENMEYER, P.; HOTTIER, P. Contrôle dela planimétried'une base de données vectorielle: une nouvelle méthode basée sur la distance de Hausdorff: la méthode du contrôle linéaire. Bulletin SFPT, v. 1, n. 137, p. 6-11, 1995.

ANTUNES, M. A. H.; SIQUEIRA, J. C. S. Características das imagens RapidEye para mapeamento e monitoramento e agrícola e ambiental. In: Simpósio Brasileiro de Sensoriamento Remoto, 2013, Foz do Iguaçu-PR. Anais do XVI Simpósio Brasileiro de Sensoriamento Remoto, INPE, 2013.

ARCANJO, D. R., ANJOS, C. S. Análise da Acurácia Posicional Planimétrica de Imagem Orbital do Sensor PAN/CBERS-4. In: Simpósio Brasileiro de Sensoriamento Remoto, 2019, Santos-SP. Anais do XIX Simpósio Brasileiro de Sensoriamento Remoto, INPE, 2019.

BARBOSA L. S., MARTINS C. T., SANTOS A. P., MEDEIROS N. G., FERREIRA I. O. Avaliação da acurácia posicional planimétrica das ortoimagens Sentinel 2A / Sensor MSI nas regiões de Alvinópolis e Viçosa, MG. In: Congresso Brasileiro de Cartografia, 2017, Rio de Janeiro-RJ. Anais do XXVII Congresso Brasileiro de Cartografia e XXVI Exposicarta, 2017, p. 163-168.

BRASIL, Decreto ${ }^{\circ} 89.817$ de 20 de junho de 1984. Normas Técnicas da Cartografia Nacional. Diário Oficial da União, Brasília, 20 de junho de 1984.

CASTEJON, E. F.; FONSECA, L.; MARIA G.; ARCANJO, J. S. Melhoria da geometria e posicionamento de imagens orbitais de média resolução: Um experimento com dados CBERS-CCD. In: Simpósio Brasileiro de Sensoriamento Remoto, 2013, Foz do Iguaçu-PR. Anais XVI Simpósio Brasileiro de Sensoriamento Remoto, INPE, 2013.

CELESTINO, V. S.; SALDANHA, D. L.; ROCHA, R. S. Avaliação da qualidade de produtos gerados a partir de imagem Quickbird através do PEC-Brasileiro. In: Simpósio Brasileiro de Sensoriamento Remoto, 2007, Florianópolis-SC. Anais XIII Simpósio Brasileiro de Sensoriamento Remoto, INPE, 2007, p. 507-514. 
CUNHA, M. M.; SECATTO G. Z.; GALINDO J. R. F.; SANTOS A. P. dos. Proposta de um método de avaliação da acurácia posicional baseado na modificação do Buffer Simples. Revista Brasileira de Cartografia, 2019.

DAL POZ, A. P.; GALO, M.; FERREIRA, F. M. Metodologias para a avaliação geométrica de feições cartográficas. In: Colóquio Brasileiro de Ciências Geodésicas, 2001, Curitiba-PR. Anais do II Colóquio Brasileiro de Ciências Geodésicas, 2001.

DIRETORIA DO SERVIÇO GEOGRÁFICO (DSG). Especificação Técnica para Controle de Qualidade de Dados Geospaciais (ET-CQDG), Brasil, 2016. Disponível em: https://bdgex.eb.mil.br/portal/index.php?option=com_content $\&$ view=article\&id=81\&Itemid=353\&lang= pt\#: :text=ET\%2DEDGV\%203.0,para\%20Governo\%20Eletr\%C3\%B4nico\%20no\%20Brasil.>. Acesso em: 02 mai. 2021.

DIRETORIA DO SERVIÇO GEOGRÁFICO (DSG). Especificação Técnica para a Estruturação de Dados Geoespaciais Vetoriais de Defesa da Força Terrestre (ET-EDGV), Brasil, 2018. Disponível em: https://bdgex.eb.mil.br/portal/index.php?option=com_content $\&$ view $=$ article \&id=81\&Itemid=353\&lang $=$ pt\#: :text=ET\%2DEDGV\%203.0,para\%20Governo\%20Eletr\%C3\%B4nico\%20no\%20Brasil.>. Acesso em: 02 mai. 2021.

EUROPEAN SPACE AGENCY (ESA). Earth Observation Data, 2016. Disponível em: <https://sentinel.esa.int/web/sentinel/user-guides/sentinel-2-msi>. Acesso em: 06 jul 2020.

FERREIRA, L. F.; CINTRA, J. P. Quantificação de discrepância entre feições lineares por retângulos equivalentes. Revista Brasileira de Cartografia, Geodésia, Fotogrametria e Sensoriamento Remoto, v. 51. p. 1-8, 1999.

FERREIRA, R. D., SILVA, L. S. L., COELHO A. L., MARANHÃO, M. R. A., OLIVEIRA, L. F., SOARES, R. A. Avaliação da qualidade posicional de ortoimagens RapidEye. Revista Brasileira de Geografia, v. 61, n. 1, p. 99-108, 2016.

FERREIRA, D. L., MARAMBAIA, F. G., JUNIOR, E. J. S. Avaliação do padrão de exatidão cartográfica de imagem do sensor Wordview. XVIII Simpósio Brasileiro de Sensoriamento Remoto, 2017.

FONSECA, I. G. R. Avaliação da acurácia posicional tridimensional utilizando feições lineares. 2018. Dissertação (Mestrado em Engenharia Civil) - Programa de Pós-Graduação em Engenharia Civil, Universidade Federal de Viçosa, Viçosa, 2018.

FRAZÃO, P. L., FERREIRA, S. P., BOGGIONE, G. A., NAZARENO, N. R. X. Avaliação do padrão de exatidão cartográfica das imagens do satélite CBERS 4. In: Simpósio Brasileiro de Sensoriamento Remoto, 2017, Santos-SP. Anais do XVIII Simpósio Brasileiro de Sensoriamento Remoto, 2017.

GALO, M.; CAMARGO, P. O. O uso do GPS no controle de qualidade de cartas. In: Congresso Brasileiro de Cadastro Técnico Multifinalitário, 1994, Florianípolos-SC. Anais do $1^{\circ}$ Congresso Brasileiro de Cadastro Técnico Multifinalitário, 1994, p. 41-48.

GALO, M.; DAL POZ, A. P.; FERREIRA, F. M. O uso de feições no controle de qualidade em cartografia. In: Congresso Brasileiro de Cartografia, 2001, Porto Alegre-RS. Anais do XX Congresso Brasileiro de Cartografia, 2001.

GOODCHILD, M.; HUNTER, G. A simple positional accuracy for linear features. International Journal Geographical Information Science. v. 11, n. 3, p. 299-306,1997.

GOOGLE EARTH ENGINE (GEE). Earth Engine Data Catalog, 2017. Disponível em: <https://developers.google.com/earth-engine/datasets/catalog/COPERNICUS_S2_SR\#description>. Acesso em: 11 jul 2020.

GORELICK, N. HANCHER, M., DIXON, M., ILYUSHCHENKO, S., THAU, D., MOORE, R. Google Earth Engine: Planetary-scale geospatial analysis for everyone. Remote Sensing of Environment, v. 202, p. 18-27, 2017.

HAIR JÚNIOR, J. F.; BLACK, W. C.; BABIN, B. J.; ANDERSON, R. E.; TATHAM, R. L. Analise Multivariada de Dados. $6^{\text {a }}$ ed. Porto Alegre: Bookman, 2009. 
INSTITUTO BRASILEIRO DE GEOGRAFIA E ESTATÍSTICA (IBGE). Bases Cartográficas Contínuas. Rio de Janeiro, 2021. Disponível em: < https://www.ibge.gov.br/geociencias/cartas-e-mapas/basescartograficas-continuas.html>. Acesso em: 02 jun. 2021.

INSTITUTO BRASILEIRO DE GEOGRAFIA E ESTATÍSTICA (IBGE). Geociências. Imagens do território. Imagens corrigidas. RJ25. Metadados do produto Ortofoto 1:25.000 do Projeto RJ25. Rio de Janeiro, 2010. Disponível em: <https://www.ibge.gov.br /geociencias/imagens-do-territorio/imagenscorrigidas/10852-ortomosaicos.html? =\&t=downloads $>$. Acesso em: 25 mai. 2020.

INSTITUTO BRASILEIRO DE GEOGRAFIA E ESTATÍSTICA (IBGE). Avaliação da Qualidade de Dados Geoespaciais. Manuais Técnicos em Geociências, Rio de Janeiro, 2019a. Disponível em: < https://www.ibge.gov.br/geociencias/metodos-e-outros-documentos-de-referencia/revista-e-manuaistecnicos/15826-manual-tecnico-em-geociencias.html?edicao=25125\&t=sobre >. Acesso em: 31 mai. 2021.

INSTITUTO BRASILEIRO DE GEOGRAFIA E ESTATÍSTICA (IBGE). Geociências. Cartas e mapas. Bases cartográficas contínuas. Estado de Sergipe - 1:100 000. Rio de Janeiro, 2019b. Disponível em: $<$ https://www.ibge.gov.br/geociencias/cartas-e-mapas/bases-cartograficas-continuas/15807estados.html?=\&t=saiba-mais-geociencias $>$. Acesso em: 25 mai. 2020.

JÚNIOR, C. C., PEREIRA, G. H. A., FRONZA, G., DEPPE, F. Avaliação da Qualidade Posicional de Ortoimagens ALOS/AVNIR2. In: Simpósio Brasileiro de Sensoriamento Remoto, 2019, Santos-SP. Anais XIX Simpósio Brasileiro de Sensoriamento Remoto, INPE, 2019, ISBN: 978-85-17-00097-3.

LA VEGA, P. G. de; ARIZA, F. J.; MOZAS-CALVACHE, A. T. Models for positional accuracy assessment of linear features: 2D and 3D cases. Survey Review, v. 48, n. 350, p. 347-360, 2016.

LONGLEY, P. A.; GOODCHILD, D. J M; RHIND, D. W. Sistema de Informações Geográficas. Bookman Companhia Editora Ltda, 2013.

MELLO, C. H. P. Gestão da qualidade. São Paulo: Pearson Education do Brasil. $1^{\circ}$ ed. São Paulo, 2011. $173 p$.

MENEZES, R. R. V., LISBOA, M. H. M., SANTOS, A. D. P., DIAS, J. S. Avaliação da acurácia planimétrica das imagens do Google Earth para produção de base cartográfica. Revista Brasileira de Cartografia, v. 71, n. 2, p. 367-391, 2019.

MONTGOMERY, D. C.; RUNGER, G. C. Applied Statistics and Probability for Engineers. $3^{\text {a }}$ ed. New York: John Wiley \& Sons, 2002.976 p.

MOZAS, A. T; ARIZA, F. J. New method for Positional Quality Control in Cartography Based on Lines. A Comparative Study of Methodologies. International Journal of Geographical Information Science, v. 25, n. 10, p. 1681-1695, 2011.

MOREIRA, J. M; OLIVEIRA, G. A.; SILVA, P. L.; SANTOS, A. P.; MARQUES, E. T. Avaliação da qualidade posicional planimétrica de ortofotos usadas no cadastro territorial multifinalitário através de feições lineares. In: Congresso Brasileiro de Cadastro Técnico Multifinalitário e Gestão Territorial, Florianópolis-SC, 2018. Anais do VII Congresso Brasileiro de Cadastro Técnico Multifinalitário e Gestão Territorial, 2018, p. 1-8.

NETO, F. de D. F; JUNIOR, J. G.; BOTElHO, M. F.; SANTOS, A. de P. dos; NASCIMENTO, L. A.; FONSECA, A. L. B. Avaliação da Qualidade Posicional de dados espaciais gerados por VANT utilizando feições pontuais e lineares para aplicações cadastrais. Boletim de Ciências Geodésicas, v. 23, n. 1, 2017.

OLIVEIRA, W. N.; MIZIARA, F.; FERREIRA, N. C. Mapeamento do Uso e Cobertura do Solo de Moçambique Utilizando a Plataforma Google Earth Engine. Anuário do Instituto de Geociências, v. 42, n. 1, p. 336-345, 2019.

PESSANHA, M. S., ANTUNES, M. A. H. Avaliação da qualidade posicional planimétrica de imagens MSI do Sentinel-2A: estudo de caso do município Dom Pedrito-RS. In: Simpósio Brasileiro de Sensoriamento Remoto, 2019, Santos-SP. Anais do XIX Simpósio Brasileiro de Sensoriamento Remoto, 2019. 
RAMIREZ, J. R.; ALI, T. Progress in metrics development to measure positional accuracy of spatial data. Proceedings of the 21st ICA Conference, 2003.

RIBEIRO, J. I. Métodos estatísticos aplicados ao controle da qualidade. $1^{\circ}$ ed. Viçosa, Editora: Universidade Federal de Viçosa, 2013. 274p.

REZENDE P. S.; MARQUES D. V.; ROSA, R. Uso de dados do Sentinel-2 para cálculo de NDVI com base nos valores da refletância aparente e de superfície. In: Simpósio Brasileiro de Sensoriamento Remoto, 2019, Santos-SP. Anais do XVIII Simpósio Brasileiro de Sensoriamento Remoto, 2017.

SANTOS, A. P.; MEDEIROS, N. G.; SANTOS, G. R.; RODRIGUES, D. D. Controle de qualidade posicional em dados espaciais utilizando feições lineares. Boletim de Ciências Geodésicas, v. 21, n. 2, 2015.

SANTOS, A. P; MEDEIROS, N. D. G.; SANTOS, G. R. D.; RODRIGUES, D. D. Avaliação da acurácia posicional planimétrica em modelos digitais de superfície com o uso de feições lineares. Boletim de Ciências Geodésicas, v. 22, n. 1, 2016.

SHAPIRO, S. S.; WILK, M. B. An analysis of variance test for normality (complete samples). Biometrika, v. 52, n. 3/4, p. 591-611, 1965.

SOUZA, V. C. O. PAREDE, D. A., VOLPATO, M. M. L., ALVES, H. M. R. Aplicações do Google Earth Engine na cafeicultura do sul de Minas Gerais. In: Simpósio de Pesquisa dos Cafés do Brasil, 2019, Vitória-ES. X Simpósio de Pesquisa dos Cafés do Brasil, 2019, ISSN: 1984-9249.

TVEITE, H.; LANGAAS, S. An accuracy assessment method for geographical line data sets based on buffering. International Journal of Geographical Information Science, v. 13, n. 1, 1999.

VERGARA, O. R., KURKDJIAN, M. L. N. O., D’ALGE, J. C. L., PEREIRA, M. N. Conteúdo informativo e exatidão geométrica de dados TM-Landsat analógicos para atualização de cartas topográficas. In: Congresso Brasileiro de Cartografia, 1999. Congresso Brasileiro de Cartografia, v. 18, 1999.

VIEIRA, C. A. O.; MATHER, P. M.; BORGES, P. A. F. Assessing the positional accuracy of remotely sensed products. In: International Symposium on Spatial Accuracy Assessment in Natural Resources and Environmental Sciences, 2002, Melbourne, Australia. 5th International Symposium on Spatial Accuracy Assessment in Natural Resources and Environmental Sciences, 2002.

XU, F., Li, Z., ZHANG, S., HUANG, N., QUAN, Z., ZHANG, W., PRISHCHEPOV, A. V. Mapping Winter Wheat with Combinations of Temporally Aggregated Sentinel-2 and Landsat-8 Data in Shandong Province. Remote Sensing, China, v. 12. n. 12, p. 2065-2020, 2020.

ZANETTI, J., PAULA, R. M., SANTOS, A. D. P., MEDEIROS, N. G. Avaliação da acurácia posicional planimétrica de ortoimagens disponibilizadas nos sistemas de informações geográficas. Revista Brasileira de Cartografia, v. 68, n. 7, p. 1341-1352, 2016.

\section{Biografia do autor principal}

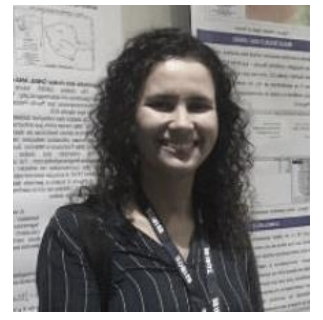

Priscila Almeida de Oliveira, nascida em Altamira, Pará. Graduanda em Engenharia de Agrimensura e Cartográfica na Universidade Federal Rural do Rio de Janeiro (UFRRJ), Seropédica.

Esta obra está licenciada com uma Licença Creative Commons Atribuição 4.0 Internacional - CC BY. Esta licença permite que outros distribuam, remixem, adaptem e criem a partir do seu trabalho, mesmo para fins comerciais, desde que lhe atribuam o devido crédito pela criação original. 